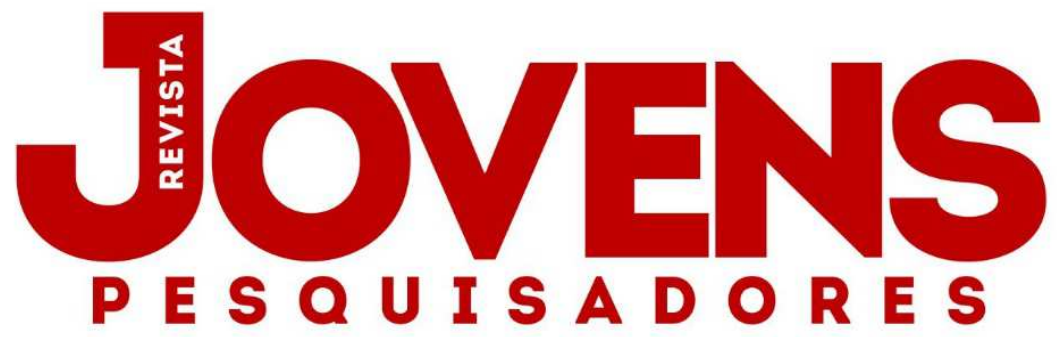

Doi: 10.17058/rjp.v8i1.12121

Recebido em: 22/05/2018

Aceito em: 02/07/2018

\title{
AVALIAÇÃO DE DIFERENTES MÉTODOS DE SECAGEM DA BIOMASSA DE MICROALGA Chlorella vulgaris
}

\author{
FORNAISER, F.1; SOUZA, M. P. ${ }^{2}$; BENITEZ, L. B. ${ }^{3}$; HOELTZ, M. ${ }^{3}$; SCHNEIDER, R. C. S. ${ }^{4}$ \\ PALAVRAS CHAVE: Microalga. Biomassa. Secagem. Lipídios. CG-EM.
}

\section{RESUMO}

Microalgas apresentam alta variedade biológica e podem ser aplicados em vários setores. A separação destes microrganismos é um desafio, uma vez que apresentam baixas densidades e são encontradas em suspensão no meio de cultura. Para otimizar o processo de secagem da biomassa das microalgas, o objetivo deste trabalho foi otimizar o uso do spray dryer em relação a secagem por estufa e por liofilização, bem como reconhecer o rendimento de biomassa, o teor lipídico, a composição dos ácidos graxos e a composição elementar (CHNS) para cada método testado. A secagem de biomassa de Chlorella vulgaris por spray dryer provou ser uma técnica alternativa mais rápida e eficiente para ser empregada em escala laboratorial.

\section{EVALUATION OF DRYING METHODS OF MICROALGAE BIOMASS Chlorella vulgaris}

\author{
KEYWORDS: Microalgae. Biomass. Drying. Lipids. GC-MS.
}

\begin{abstract}
Microalgae presents high biological variety and can be applied in several sectors. The separation of these microorganisms is a challenge since they have low densities and are found in suspension in the culture medium. In order to optimize biomass drying step of microalgae, the aim of this work was to optimize the use of spray dryer if compared to oven furnace, as well as to recognize lipid composition, biomass yield, fatty acid composition and elemental composition (CHNS) for each method tested. Chlorella vulgaris biomass drying with spray dryer proved to be faster and efficient alternative technique to be employed in laboratory scale.
\end{abstract}

\footnotetext{
1 Graduada em Química pela Universidade de Santa Cruz do Sul.

2 Acadêmica do curso de Licenciatura em Química na Universidade de Santa Cruz do Sul.

3 Docentes do Departamento de Biologia e Farmácia na Universidade de Santa Cruz do Sul.

4 Docente do Departamento de Química e Física na Universidade de Santa Cruz do Sul.
} 


\section{INTRODUÇÃO}

As microalgas são microrganismos que se adaptam facilmente com as condições ambientais, pois sua estrutura celular é consideravelmente simples. Devido a sua elevada taxa de crescimento, possuem também uma alta produtividade de lipídios, uma vez que seus metabólitos são alterados para a acumulação natural de triacilgliceróis (ABOMOHRA et al., 2016). Além do interesse na produção de biocombustíveis, também apresentam destaque para a produção de alimentos e produtos de alto valor agregado. Quando os fatores químicos e físicos do meio de cultura são alterados, possuem a capacidade de produzir lipídios específicos, como ácidos graxos poliinsaturados, os quais auxiliam na prevenção de doenças cardiovasculares e diminuem a incidência de câncer, lecitinas, policetídeos e carotenóides. Além disso, podem ser utilizadas para o controle da poluição atmosférica e no tratamento de águas residuais (HU et al., 2008, MATA et al., 2010, ARAUJO et al., 2013, BAl et al., 2015).

O teor lipídico das microalgas varia dependendo da sua composição e o meio de cultivo. Através da fotossíntese e de fontes de carbono como o $\mathrm{CO}_{2}$, ou a partir de fontes de carbono orgânico como glicose, é possível sintetizar diferentes ácidos graxos. As microalgas, em comparação com outras culturas energéticas como soja, palma e outros óleos vegetais, podem produzir até 100 vezes mais óleo. Dentre os principais ácidos graxos presentes na biomassa de microalgas estão o ácido oleico e o linoleico (LEE et al., 2010, CAMPBELL et al., 2011, MAHMOUD et al., 2015).

A separação das microalgas ainda é um grande desafio visto que possuem baixas densidades e estão em suspensão no meio de cultivo. É necessário obter a biomassa separada, úmida, e em seguida realizar a secagem (MAHMOUD et al., 2015). Assim, para a obtenção dos lipídios, a secagem é uma etapa importante do processo. Embora possa consumir elevadas quantidades de energia, proporciona uma melhor extração dos lipídios na etapa seguinte (CHEN et al., 2015).

Diversos métodos de secagem podem ser encontrados na literatura, como por exemplo, liofilização, secagem em tambor, estufa, spray dryer e leito fluidizado de secagem (DESMORIEUX et al., 2010, FLORENTINO DE SOUZA SILVA et al., 2014, GULDHE et al., 2014).

A escolha do método de secagem deve ser bastante estudada uma vez que o uso de temperaturas maiores que $50{ }^{\circ} \mathrm{C}$ e elevadas pressões podem degradar componentes celulares importantes das microalgas. Isso ocorre, por exemplo com a secagem por estufa, que por utilizar aquecimento por maior tempo, pode modificar as propriedades físicas e químicas da célula, principalmente a capacidade de reter lipídio, o que interfere na qualidade do produto final. Já o método de secagem por liofilização garante maior estabilidade quando relacionado aos lipídios produzidos, mas também pode romper as células e desestabilizar os lipídios durante o congelamento (BENNAMOUN et al., 2015, CHEN et al., 2015). 
A secagem de microalgas por spray dryer é uma das técnicas mais utilizadas, eficientes e muito aplicada na indústria (SHOW et al., 2015) e sua aplicação na secagem de biomassa de microalgas ainda é diminuta frente a secagem em estufa e por liofilização.

Segundo Chen et al. (2015), a secagem por spray dryer é vantajosa, os produtos obtidos por esta técnica são majoritariamente destinados para fins alimentícios, pois permite maior conservação dos nutrientes, como as proteínas presente na célula microalgal, embora em seus resultados pode ser observado que o emprego dessa técnica de secagem pode desestabilizar outros componentes celulares, como os carotenoides. 0 mesmo foi observado por AHMED et al. (2015) quando empregou o spray dryer na secagem da espécie de microalga Haematococcus pluvialis sp., visando obter maior rendimento de astaxantina, porém este método também apresentou baixos rendimentos no produto final.

Pohndorf et al. (2016) utilizaram a secagem por spray dryer em microalgas Spirulina sp. e constataram que este método favoreceu um melhor rompimento celular e aumentou o rendimento lipídico das amostras secas com temperaturas acima de $50{ }^{\circ} \mathrm{C}$.

0 emprego do método de secagem, está relacionado com o custo energético, tempo de processo e da aplicação da biomassa seca, embora a secagem por liofilização seja uma das técnicas que permite maior estabilidade celular, o custo energético e o tempo é muito maior quando comparado com a secagem por estufa ou por spray dryer, sendo este um fator que impulsiona a pesquisa com spray dryer, uma vez que já tem aplicação industrial por reduzir o tempo de processo (BENNAMOUN et al., 2015).

Neste contexto, o presente trabalho tem como objetivo aplicar o método de secagem por spray dryer da biomassa de microalga, a fim de avaliar os efeitos da secagem, verificar o melhor rendimento de biomassa e também analisar o perfil lipídico das amostras.

\section{MATERIAIS E MÉ TODOS}

\subsection{CULTIVO DA MICROALGA}

A espécie de microalga Chlorella vulgaris, foi cultivada em fotobiorreatores tubulares do tipo coluna de bolhas, localizado no Parque Científico e Tecnológico da Universidade de Santa Cruz do Sul. Dois cultivos foram realizados, por um período de 12 dias cada, sendo controlados temperatura (25 ${ }^{\circ} \mathrm{C}$ ), iluminação (lâmpadas de $32 \mathrm{~W}$ ), com aporte de $\mathrm{CO}_{2}$ e meio de crescimento. A microalga se desenvolveu em um meio contendo $3 \mathrm{~g} \mathrm{~L}^{-1}$ de N:P:K (18:6:18 m/m) adquirido em loja agropecuária local.

0 crescimento da microalga foi acompanhada através da contagem de células por câmara de Newbauer, utilizando microscópio óptico (B1 Series Quimis Motic ${ }^{\circledR}$ ) e a partir da densidade 
celular determinada por espectrofotometria (UV-vis Q798U Quimis ${ }^{\circledR}$ ) a $682 \mathrm{~nm}$. A amostra foi diluída a fim de se obter absorvâncias entre 0,1 - 1,0, conforme a curva analítica previamente obtida, correlacionando a contagem celular com a absorvância do meio.

\subsection{SEPARAÇÃO E SECAGEM DA BIOMASSA}

\subsubsection{DECANTAÇÃO}

A pré-concentração da biomassa, foi realizada a partir de $1 \mathrm{~L}$ de inóculo, através do processo de decantação, por 3 dias e sob refrigeração $\left(10^{\circ} \mathrm{C}\right)$. Através da técnica por aspersão, utilizando bomba de vácuo (Prismatec ${ }^{\circledR} 1312 \mathrm{VC}$ ), sendo retirado o sobrenadante remanescente.

\subsubsection{SPRAY DRYER}

A secagem por spray dryer (B-290 Buchi ${ }^{\circledR}$ ) foi realizada utilizando $1 \mathrm{~L}$ de amostra de cada cultivo, homogeneizadas previamente. A secagem foi realizada com fluxo de $\mathrm{N}_{2}$, diâmetro do orifício de aspersão de $0,7 \mathrm{~mm}$, a temperatura de entrada utilizada foi de $110{ }^{\circ} \mathrm{C}$, e temperatura de saída de $60{ }^{\circ} \mathrm{C}$, aspiração da amostra em 100\%, bomba peristáltica em $25 \%$ e 2 pulsos programados durante o processo.

\subsubsection{ESTUFA}

A secagem da biomassa foi realizada em estufa (Biofoco ${ }^{\circledR}$ ), utilizando $1 \mathrm{~L}$ de cada cultivo. Para essa secagem, a biomassa foi separada previamente por centrifugação (206 BL Excelsa II $®)$ ). A biomassa úmida foi disposta em placas de petry e secas a uma temperatura de $50{ }^{\circ} \mathrm{C}$ por 24 horas.

\subsection{DETERMINAÇÃO DE LIPÍDIOS TOTAIS}

As extrações lipídicas das biomassas secas foram realizadas através do método descrito por Bligh and Dyer (1959). Inicialmente foram pesados $300 \mathrm{mg}$ de biomassa seca em tubo de polipropileno e, posteriormente, adicionou-se $6 \mathrm{~mL}$ de um mistura 1:2 (v/v) clorofórmio: metanol. Os tubos foram sonicados por 45 minutos em ultrassom (ECO-SONICS Q 1.8/25®) e deixados em repouso no congelador por $4 \mathrm{~h}$. Dando sequência, as amostras foram colocadas novamente no ultrassom por 15 minutos e centrifugadas (206 BL Excelsa II ®), à 2000 rpm por mais 15 minutos. Repetiu-se essa etapa por mais dois ciclos. A fase lipídica (sobrenadante) foi reservada em novo tubo. À biomassa residual foram adicionados $3 \mathrm{~mL}$ da mistura 1:2 (v/v) clorofórmio-metanol e novamente 
centrifugado por 15 minutos. 0 sobrenadante foi recuperado junto ao novo tubo, ao qual foram adicionados $4 \mathrm{~mL}$ de água deionizada e $2 \mathrm{~mL}$ de clorofórmio, repetindo-se o ciclo de centrifugação. A fase orgânica foi reservada em novo frasco pré-pesado e foi evaporado o solvente. Após a evaporação total do solvente, o frasco foi pesado obtendo-se o rendimento lipídico.

\subsection{ANÁLISE POR CROMATOGRAFIA GASOSA ACOPLADA A ESPECTROMETRIA DE MASSAS}

Ao óleo extraído da biomassa, foram adicionados $6 \mathrm{~mL}$ de uma solução metanólica de $\mathrm{NaOH}$ $2 \%$ e aqueceu-se sob refluxo por 20 minutos. Adicionou-se, gota a gota, $7 \mathrm{~mL}$ de solução $\mathrm{BF}_{3} /$ Metanol. Após 4 minutos, $5 \mathrm{~mL}$ de heptano foram acrescentados e deixou-se a amostra em refluxo por 2 minutos. Posteriormente, o balão foi retirado do aquecimento e resfriado a temperatura ambiente. Uma solução saturada de $\mathrm{NaCl}$ foi acrescida e agitada suavemente até a observação de duas fases. Transferiu-se para um tubo de ensaio e a fase superior foi separada para a adição de $\mathrm{Na}_{2} \mathrm{SO}_{4}$ anidro. A parte líquida foi retirada e armazenada para posterior análise cromatográfica (BRODNJAK-VONČINA et al., 2005).

A análise quantitativa dos lipídios extraídos, foi realizada por cromatografia gasosa com detecção por ionização em chama (CG-MS) em um equipamento Shimadzu ${ }^{\circledR}$ QP 2010 Plus equipado com Injetor Automático AOC 20i, sendo as amostras separadas em uma coluna capilar Zbwax (30 m x 0,25 mm x 0,25 $\mu \mathrm{m}$ ). 0 hélio (White Martins Gases Industriais, Canoas, Brasil, 99,999\%) foi utilizado como gás de arraste e a sua taxa de fluxo foi de $1 \mathrm{~mL} \mathrm{~min}^{-1}$. A programação de temperatura do forno foi $70^{\circ} \mathrm{C}\left(4^{\circ} \mathrm{C} \mathrm{min}-1\right)$, até $240{ }^{\circ} \mathrm{C},\left(5^{\circ} \mathrm{C} \mathrm{min}-1\right)$, até $250{ }^{\circ} \mathrm{C}$, totalizando 49,5 minutos de análise. Temperatura do detector $300{ }^{\circ} \mathrm{C}$, temperatura do injetor $250{ }^{\circ} \mathrm{C}$, operado no modo "split" 1:10 e volume de injeção de $1 \mu \mathrm{L}$. A identificação dos compostos presentes foi efetuada pela comparação dos tempos de retenção com padrões comerciais de ésteres metílicos (Supelco Analitycal ${ }^{\circledR}$ - Bellefonte, Pennsylvania, USA).

\subsection{ANÁLISE ELEMENTAR}

Foi realizada a análise das biomassas secas, em analisador elementar CHNS (PerkinElmer 2400 Series II), com temperatura de combustão de $975^{\circ} \mathrm{C}$, a de redução $500^{\circ} \mathrm{C}$. As amostras (2 mg) foram pesadas em balança AD 6000 (PerkinElmer). 


\section{RESULTADOS E DISCUSSÕES}

\subsection{CURVA DE CRESCIMENTO}

A máxima densidade celular obtida no inóculo alimentado com $3 \mathrm{~g} \mathrm{~L}^{-1}$ de $\mathrm{N}: \mathrm{P}: \mathrm{K}$ foi de $1,22 \times 10^{7}$ cel $\mathrm{mL}^{-1}$. Observa-se na figura 2 , que em 3 dias a microalga permaneceu na fase de adaptação, e a partir do quarto dia de cultivo, ocorreu o crescimento exponencial das células. 0 sistema foi interrompido no décimo segundo dia de cultivo, sendo observado a fase estacionária do crescimento e não foi observado a fase de declínio das células.

No estudo de Lee et al. (2010) foi constatado, ao analisar três espécies diferentes de microalgas, que a espécie Chorella vulgaris e Scenedesmus sp. se desenvolveram e tiveram maior rendimento de biomassa, $7,42 \mathrm{~g} \mathrm{~L}^{-1}$ e $7,14 \mathrm{~g} \mathrm{~L}^{-1}$ respectivamente, em apenas 7 dias de cultivo, a espécie Botryococcus sp, também analisada no estudo, foi cultivada em mais tempo, 14 dias, para se ter um maior rendimento de biomassa $\left(3,5 \mathrm{~g} \mathrm{~L}^{-1}\right)$, embora as duas primeiras espécies apresentaram melhores rendimentos. As condições utilizadas não representaram uma maior taxa de crescimento, no entanto, a biomassa obtida foi suficiente para a obtenção de

Baierle et al. (2015), ao cultivar a espécie Desmodesmus subspicatus, também observaram um rendimento próximo ao que foi obtido neste trabalho $\left(3,7 \mathrm{~g} \mathrm{~L}^{-1}\right)$ no mesmo equipamento. Essas variações de crescimento celular que ocorrem podem estar relacionadas com o tipo de cultivo e disponibilidade de nutrientes existentes no meio de desenvolvimento da microalga (LIU et al., 2012, HO et al., 2014).

Figura 1. Crescimento Celular das microalgas empregadas no estudo de secagem.

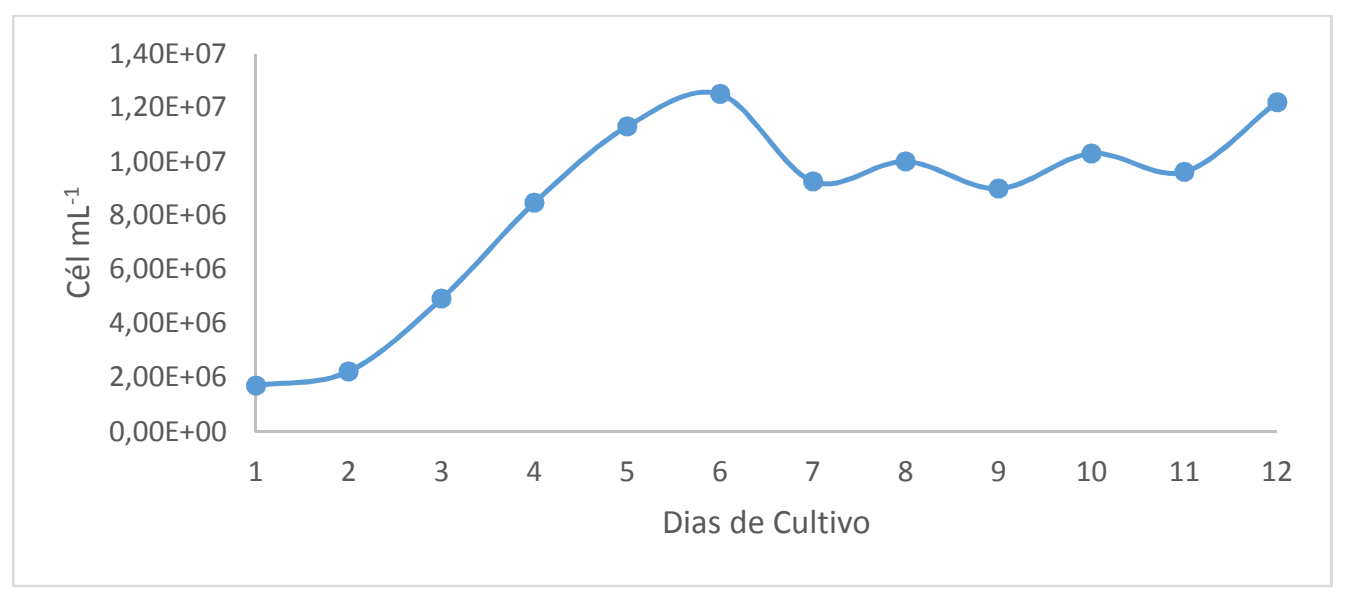

\subsection{RENDIMENTO DAS SECAGENS}

A secagem é uma etapa fundamental no processo de obtenção da biomassa de microalgas, uma vez que a remoção da água, aumenta a extração lipídica (GULDHE et al., 2014, CHEN et al., 
2015). Após os cultivos, a biomassa da microalga Chorella vulgaris foi armazenada em frascos apropriados sob refrigeração $\left(10^{\circ} \mathrm{C}\right)$, passando para a etapa de secagem. Para as secagens realizadas por estufa foi necessário realizar a centrifugação do inóculo, sendo retirado aproximadamente $1 \mathrm{~L}$ de sobrenadante ao ser concentrada a biomasssa. Para a secagem por spray dryer, com concentração da biomassa, foi retirado $800 \mathrm{~mL}$ de sobrenadante. A tabela 1, apresenta os rendimentos obtidos de biomassa seca a partir de cada método.

Tabela 1. Rendimento de biomassa seca obtida pelos diferentes métodos de secagem.

\begin{tabular}{cccc}
\hline \multirow{3}{*}{ Método de Secagem } & \multicolumn{2}{c}{ Condição } & Rendimento sem N:P:K (g L-1) \\
\cline { 2 - 4 } & $\begin{array}{c}\text { Concentração N:P:K } \\
\left(\mathrm{g} \mathrm{L}^{-1}\right)\end{array}$ & Temperatura $\left({ }^{\circ} \mathrm{C}\right)$ & Média \\
\hline \multirow{2}{*}{ Spray dryer } & 3 & 110 & $0,3 \pm 0,1$ \\
& 3 & 110 & $0,7 \pm 0,2$ \\
\hline Estufa & 3 & 50 & $0,2 \pm 0,0$ \\
\hline
\end{tabular}

A partir da análise estatística ANOVA, comparou-se os rendimentos dos diferentes métodos de secagem. Para a secagem por spray dryer, quando foi realizado a secagem pré-concentrando o inóculo, houve diferença significativa $(p>0,05)$, em relação a secagem sem pré concentração, uma vez que houve redução do consumo de energia, de $\mathrm{N}_{2}$ e tempo de secagem. 0 rendimento de biomassa foi maior, visto que no sobrenadante ainda permanecem partículas de menor densidade e o NPK que está diluído no meio.

No conteúdo total de biomassa obtida, pode se observar uma grande quantidade de N:P:K, este que permanece em suspensão no meio. Isso pode ser visto a partir da secagem de uma solução de $1 \mathrm{~L}$ de $\mathrm{N}: \mathrm{P}: \mathrm{K}$, onde encontrou-se $50 \%$ de massa do nutriente envolvido na biomassa. Para aumentar o rendimento em biomassa é importante estudar a secagem em outras temperaturas, uma vez que, quando a temperatura de secagem é maior pode ocorrer perdas da biomassa, pois as mesmas ficam aderidas nas paredes do equipamento de secagem (HUGO et al., 2016).

Concentrar a biomassa para realizar a secagem, permite diminuir o custo de análise e remove grande parte do N:P:K dissolvido no meio, que pode interferir na extração lipídica da etapa seguinte, assim como mascara o rendimento obtido.

Comparando as duas metodologias de secagens à quente (spray dryer e estufa), com a mesma condição de cultivo ( $\left.3 \mathrm{~g} \mathrm{~L}^{-1}\right)$, observou-se que houve diferença significativa $(p>0,05)$, entre as secagens, uma vez que o rendimento de biomassa seca por spray dryer foi maior em relação a biomassa seca em estufa. Portanto, a melhor condição de secagem, com base nos experimentos realizados foi a que empregou a técnica por spray dryer com temperatura de $110^{\circ} \mathrm{C}$. 


\subsection{ANÁLISE ELEMENTAR DA BIOMASSA (CHNS)}

A análise elementar indicou a composição encontrada das biomassas secas, pelos diferentes métodos de secagens e os resultados obtidos encontram-se na tabela 2.

Tabela 2. Composição Elementar da Biomassa

\begin{tabular}{cccccc}
\hline $\begin{array}{c}\text { Método de } \\
\text { Secagem }\end{array}$ & Amostra & $\begin{array}{c}\text { Temperatura } \\
\left({ }^{\circ} \mathrm{C}\right)\end{array}$ & Carbono (\%) & Nitrogênio (\%) & Enxofre (\%) \\
\hline Spray Dryer & $\begin{array}{c}\text { Meio de cultivo } \\
\text { sem microalgas }\end{array}$ & 110 & $2,2 \pm 1,0$ & $23,0 \pm 1,5$ & $13,7 \pm 0,7$ \\
& $\begin{array}{c}\text { SD - amostra } \\
\text { de meio de } \\
\text { cultivo com } \\
\text { microalgas }\end{array}$ & & $4,6 \pm 0,8$ & $9,2 \pm 1,0$ & $5,2 \pm 0,7$ \\
& $\begin{array}{l}\text { SD-amostra } \\
\text { concentrada }\end{array}$ & & $13,9 \pm 1,0$ & $8,0 \pm 0,5$ & $3,7 \pm 0,2$ \\
\hline Estufa & $\begin{array}{c}\text { Amosta } \\
\text { centrifugada e } \\
\text { separada }\end{array}$ & 50 & $40,7 \pm 0,8$ & $7,5 \pm 0,0$ & $1,5 \pm 0,3$ \\
\hline
\end{tabular}

A partir da tabela 2, é possível observar que quando se concentra a biomassa, aumenta o teor de carbono, diminuindo o teor de nitrogênio, uma vez que está sendo retirado a maior parte de sais dissolvidos do meio. Essa diminuição de nitrogênio na biomassa, aumenta a qualidade dos lipídios (SATHISH et al., 2015).

Também se observa que, as biomassas possuem teores tanto de carbono quanto de nitrogênio e enxofre. Chen et al. (2017), abordaram em seu estudo que a biomassa de microalga Chlorella vulgaris possuem altas taxas de nitrogênio e enxofre, visto que, uma das principais fontes de nutrientes para o desenvolvimento celular são baseados nesses elementos, podendo interferir na emissão de NOx e SOx quando a biomassa for aplicada na produção de biocombustíveis.

Embora seja retirado a maior parte dos sais quando se concentra a biomassa, é possível perceber, através da análise de nitrogênio total, por COT, que durante o desenvolvimento e crescimento celular, a microalga assimila aproximadamente $200 \mathrm{mg}$ do nitrogênio total disponibilizado no meio.

Pruvost et al. (2009) e Santos et al. (2013) constataram que ao diminuir o nitrogênio do meio, diminuiu também a produtividade de biomassa, porém ocorreu maior acúmulo de lipídios nas células da espécie N. oleoabundans.

A falta do nitrogênio causa um estresse celular, provocando um acúmulo de lipídios na célula, o que torna o $\mathrm{N}_{2}$ um fator determinante na produção de lipídios de microalgas (SINGH et al., 2015, DEL Río et al., 2017). 


\subsection{TEOR DE LIPÍDIOS}

Após as secagens da biomassa, foi realizada a extração dos lipídios que estão presentes na célula da microalga, através da extração química. Na extração química, empregam-se solventes que interagem com as matrizes celulares, ocorrendo a extração dos lipídios (HALIM et al., 2011).

Os lipídios são componentes celulares importantes das microalgas, podendo ser empregados para a produção de biodiesel, por exemplo. As microalgas podem conter de 1 a $70 \%$ de teor lipídico, porém algumas espécies apresentam teores menores, a espécie Chlorella pode apresentar teores lipídicos entre 14 e 22\% (SONG et al., 2016), podendo variar dependendo do tipo de cultivo e espécie.

0 nitrogênio é um nutriente fundamental para o metabolismo e crescimento da célula. Quando ocorre o esgotamento deste, o carbono presente no meio se converte em lipídios, sendo uma estratégia comum para o acumulo de lipídios na célula da microalga(PRUVOST et al., 2009, MORENO-GARCIA et al., 2017).

Ao concentrar a biomassa através da decantação, e secá-las por spray dryer, foi possível obter um rendimento lipídico de $30 \%$, sendo esse valor maior que o encontrado por Song et al. (2016), para a espécie Chlorella, 22\% de rendimento lipídico. A tabela 3 apresenta os rendimentos alcançados.

É possível observar também que, para os métodos de secagem estufa e liofilização, os rendimentos foram próximos, ao contrário das amostras secas por spray dryer, sem concentração da amostra. 0 rendimento de lipídios nas amostras secas por spray dryer sem pré - concentração foram baixos, uma vez que o sobrenadante contendo os sais nutritivos permanece junto a biomassa quando seca, interferindo na extração lipídica.

Para Guldhe et al. (2014), os métodos de secagem liofilização e estufa empregadas no estudo, não mostraram diferença para a extração de lipídios. Pohndorf et al. (2016) e Bennamoun et al. (2015), também analisaram diferentes métodos de secagem (liofilização e spray dryer) da biomassa de microalga, e constataram que não houve diferença em relação a extração lipídica, embora possam influenciar na qualidade dos ácidos graxos, cor e características da amostra.

Tabela 3. Rendimentos lipídicos das biomassas secas em diferentes métodos de secagem.

\begin{tabular}{cccc} 
Método de & \multicolumn{2}{c}{ Condição } & $\begin{array}{c}\text { Rendimento } \\
\text { Secagem }\end{array}$ \\
\cline { 2 - 4 } & $\begin{array}{c}\text { Concentração } \\
\mathrm{N}: \mathrm{P}: \mathrm{K}\left(\mathrm{g} \mathrm{L}^{-1}\right)\end{array}$ & $\begin{array}{c}\text { Temperatura } \\
\left({ }^{\circ} \mathrm{C}\right)\end{array}$ & Média \\
\hline Spray dryer & 3 & 110 & $1,6 \pm 1$ \\
& $3^{*}$ & 110 & $30,0 \pm 7,2$ \\
\hline Estufa & 3 & 50 & $10,7 \pm 0,5$ \\
\hline
\end{tabular}

* condições obtidas com etapa prévia de pré - concentração da biomassa 
Quando se utiliza temperaturas elevada (maiores que $50^{\circ} \mathrm{C}$ ) os componentes celulares podem se deteriorar, diminuindo consideravelmente seu percentual. Assim, o método de secagem por liofilização apresenta-se mais adequado quando se deseja obter além dos lipídios, outros componentes presentes na célula da microalga, como vitaminas, carotenoides, proteínas, porém o seu alto custo desfavorece o método, uma vez que há grande consumo de energia e de tempo de processo quando comparado ao spray dryer (BENNAMOUN et al., 2015, CHEN, Ching-Lung et al., 2015, POHNDORF et al., 2016).

\subsection{PERFIL DE ÁCIDOS GRAXOS NA BIOMASSA}

O conteúdo lipídico das amostras, foi caracterizado por GC-MS. A tabela 4 apresenta os resultados obtidos.

Tabela 4. Perfil de Ésteres Metílicos dos Ácidos Graxos

\begin{tabular}{cccc}
\hline Ácidos graxos & Spray dryer (meio de cultura) & $\begin{array}{c}\text { Spray dryer (meio de cultura } \\
\text { concentrado) }\end{array}$ & $\begin{array}{c}\text { Secagem em estufa } \\
\text { (centrifugado) }\end{array}$ \\
\hline C14:0 & $1,70 \pm 0,46$ & $2,37 \pm 0,45$ & $2,34 \pm 0,01$ \\
C15:0 & $0,43 \pm 0,10$ & $0,59 \pm 0,08$ & $0,55 \pm 0,29$ \\
C16:0 & $25,14 \pm 5,36$ & $31,26 \pm 4,84$ & $37,71 \pm 0,55$ \\
C16:1 & $1,50 \pm 0,27$ & $1,57 \pm 1,18$ & $1,59 \pm 0,30$ \\
C16:2 & $7,07 \pm 2,81$ & $2,41 \pm 3,56$ & $4,18 \pm 0,16$ \\
C18:0 & $4,57 \pm 1,17$ & $2,92 \pm 0,40$ & $3,33 \pm 0,02$ \\
C18:1 & $3,77 \pm 1,39$ & $3,81 \pm 0,67$ & $4,62 \pm 0,08$ \\
C18:2 & $22,56 \pm 7,64$ & $21,47 \pm 3,21$ & $21,13 \pm 0,53$ \\
C18:3 & $10,58 \pm 7,62$ & $9,64 \pm 3,46$ & $7,50 \pm 0,60$ \\
\hline Total de Insaturados & $64,79 \pm 1,93$ & $58,98 \pm 6,28$ & $47,9 \pm 0,3$ \\
Total de Saturados & $35,47 \pm 2,07$ & $41,02 \pm 6,28$ & $52,1 \pm 0,3$ \\
\hline
\end{tabular}

Para a espécie Chlorella, é comum encontrar ésteres metílicos que contenham de 14 a 18 carbonos na cadeia, dentre eles os ácidos palmítico, oleico e o linoleico, o que a classifica como sendo uma espécie potencial para a aplicação na produção de biodiesel (LEE et al., 2010, CAMPBELL et al., 2011, CHIA et al., 2013, MAHMOUD, Eman A et al., 2015, PATEL et al., 2017). Outra espécie de microalga, T. suecica, também possui em sua composição ésteres metílicos similares ao da espécie Chlorella (HALIM et al., 2012).

Observa-se que o éster metílico do ácido palmítico (C16:0), saturado, predomina nas amostras, ocorrendo o mesmo em espécies como Spirulina e Nannochloropsis [35]. Outros ésteres metílicos saturados, podem ser encontrados nas amostras como o ácido mirístico (C14:0) e o ácido esteárico (C18:0). Estes, são conhecidos por aumentar a qualidade e melhorar o desempenho do biodiesel, assim como os ésteres insaturados oleico (C18:1), linoleico (C18:2) e linolênico (C18:3)(HUANG et al., 2015, GUPTA et al., 2016). 
Segundo Eloka-Eboka e Inambao (2017), espécies como Chlorella, Dunaliella, Senedesmus e Synechococcus possuem alto teor de ácidos graxos monoinsaturados.

Nas análises cromatográficas, o total de ésteres metílicos insaturados em todas as amostras foi maior que o teor de ésteres saturados, não observando-se uma diferença devido a processos de secagem, a não ser para uma amostra seca em estufa na qual o teor de ácidos graxos insaturados foi menor. Quando se emprega o spray dryer, pelo aquecimento ser em curto espaço de tempo, não leva a degradação das insaturações de forma visível, quando comparada aos outros métodos de secagem como estufa e liofilização. (BENNAMOUN et al., 2015, CHEN, Ching-Lung et al., 2015).

\section{CONSIDERAÇÕES FINAIS}

A partir dos métodos de secagem aplicados neste estudo, estufa, liofilização e spray dryer, foi possível obter maior rendimento de biomassa quando se empregou a secagem por spray dryer, assim como o maior rendimento lipídico foi obtido através da pré - concentração do inóculo, aplicando a mesma técnica de secagem.

A predominância dos mesmos ácidos graxos foi encontrada em todas as amostras. A técnica de secagem por liofilização mostrou-se eficiente na conservação dos ácidos graxos, principalmente para o ácido graxo linolênico (C18:3). Já para as técnicas de secagem por estufa e liofilização, os ácidos graxos palmítico (C16:0) e linoleico (C18:2), foram predominantes.

Os métodos de secagem mostraram-se adequados, no entanto, o método de secagem spray dryer pode evitar etapas anteriores de centrifugação.

Por outro lado, empregando o spray dryer é necessário considerar que elementos do meio de cultura podem ser concentrados junto à biomassa. Dependendo do uso que a biomassa receberá, este fator não será um fator que limite o uso do método.

\section{AGRADECIMENTOS}

Os autores agradecem ao CNPq e a Fapergs, pelo apoio financeiro, à UNISC e ao Centro de Excelência em Produtos e Processos Oleoquimicos e Biotecnológicos do Parque Científico e Tecnológico Regional (TecnoUNISC).

\section{REFERÊNCIAS}

ABOMOHRA, A. E.-F.; JIN, W.; TU, R.; HAN, S.-F.; EID, M. AND ELADEL, H. Microalgal biomass production as a sustainable feedstock for biodiesel: Current status and perspectives. Renewable and Sustainable Energy Reviews. Vol. 64, n. 596-606, 2016. 
AHMED, F.; LI, Y.; FANNING, K.; NETZEL, M. AND SCHENK, P. M. Effect of drying, storage temperature and air exposure on astaxanthin stability from Haematococcus pluvialis. Food Research International. Vol. 74, n. 231-236, 2015.

ARAUJO, G. S., MATOS, L. J. B. L., FERNANDES, J. 0., CARTAXO, S. J. M., GONÇALVES, L. R. B., FERNANDES, F. A. N. AND FARIAS, W. R. L., Extraction of lipids from microalgae by ultrasound application: Prospection of the optimal extraction method. Ultrasonics Sonochemistry. Vol. 20, n. 1, 95-98, 2013.

BAI, X., SCHENK, P. M., YUAN, Z., LANT, P. A. AND PRATT, S., Enhanced triacylglyceride extraction from microalgae using free nitrous acid pre-treatment. Applied Energy. Vol. 154, n. 183-189, 2015.

BAIERLE, F., JOHN, D. K., SOUZA, M. P., BJERK, T. R., MORAES, M. S. A., HOELTZ, M., ROHLFES, A. L. B., CAMARGO, M. E., CORBELLINI, V. A. AND SCHNEIDER, R. C. S., Biomass from microalgae separation by electroflotation with iron and aluminum spiral electrodes. Chemical Engineering Journal. Vol. 267, n. 0, 274-281, 2015.

BENNAMOUN, L., AFZAL, M. T. AND LÉONARD, A., Drying of alga as a source of bioenergy feedstock and food supplement - A review. Renewable and Sustainable Energy Reviews. Vol. 50, n. 1203-1212, 2015.

BLIGH, E. G. AND DYER, W. J., A rapid method of total lipid extraction and purification. Canadian journal of biochemistry and physiology. Vol. 37, n. 8, 911-917, 1959.

BRODNJAK-VONČINA, D., KODBA, Z. C. AND NOVIČ, M., Multivariate data analysis in classification of vegetable oils characterized by the content of fatty acids. Chemometrics and Intelligent Laboratory Systems. Vol. 75, n. 1, 31-43, 2005.

CAMPBELL, P. K., BEER, T. AND BATTEN, D., Life cycle assessment of biodiesel production from microalgae in ponds. Bioresource Technology. Vol. 102, n. 1, 50-56, 2011.

CHEN, C.-L., CHANG, J.-S. AND LEE, D.-J., Dewatering and drying methods for microalgae. Drying technology. Vol. 33, n. 4, 443-454, 2015.

CHEN, C.-L., HUANG, C.-C., HO, K.-C., HSIAO, P.-X., WU, M.-S. AND CHANG, J.-S., Biodiesel production from wet microalgae feedstock using sequential wet extraction/transesterification and direct transesterification processes. Bioresource Technology. Vol. 194, n. 179-186, 2015.

CHEN, C., CHEN, F., CHENG, Z., CHAN, Q. N., KOOK, S. AND YEOH, G. H., Emissions characteristics of NOx and SO2 in the combustion of microalgae biomass using a tube furnace. Journal of the Energy Institute. Vol. 90, n. 5, 806-812, 2017.

CHEN, C. L., HUANG, C. C., HO, K. C., HSIAO, P. X., WU, M. S. AND CHANG, J. S., Biodiesel production from wet microalgae feedstock using sequential wet extraction/transesterification and direct transesterification processes. Bioresource Technology. Vol. 194, n. 179-186, 2015.

CHIA, M. A., LOMBARDI, A. T., MELÃO, M. D. G. G. AND PARRISH, C. C., Lipid composition of Chlorella vulgaris (Trebouxiophyceae) as a function of different cadmium and phosphate concentrations. Aquatic Toxicology. Vol. 128-129, n. 171-182, 2013.

DEL RÍO, E., GARCíA-GÓMEZ, E., MORENO, J., G. GUERRERO, M. AND GARCÍA-GONZÁLEZ, M., Microalgae for oil. Assessment of fatty acid productivity in continuous culture by two high-yield strains, Chlorococcum oleofaciens and Pseudokirchneriella subcapitata. Algal Research. Vol. 23, n. 37-42, 2017.

DESMORIEUX, H., MADIOULI, J., HERRAUD, C. AND MOUAZIZ, H., Effects of size and form of Arthrospira Spirulina biomass on the shrinkage and porosity during drying. Journal of Food Engineering. Vol. 100, n. 4, 585-595, 2010.

ELOKA-EBOKA, A. C. AND INAMBAO, F. L., Effects of CO2 sequestration on lipid and biomass productivity in microalgal biomass production. Applied Energy. Vol. 195, n. 1100-1111, 2017.

FLORENTINO DE SOUZA SILVA, A. P., COSTA, M. C., COLZI LOPES, A., FARES ABDALA NETO, E., CARRHÁ LEITÃO, R., MOTA, C. R. AND BEZERRA DOS SANTOS, A., Comparison of pretreatment methods for total lipids extraction from mixed microalgae. Renewable Energy. Vol. 63, n. 0, 762-766, 2014.

GULDHE, A., SINGH, B., RAWAT, I., RAMLUCKAN, K. AND BUX, F., Efficacy of drying and cell disruption techniques on lipid recovery from microalgae for biodiesel production. Fuel. Vol. 128, n. 46-52, 2014. 
GUPTA, P. L., CHOI, H.-J., PAWAR, R. R., JUNG, S. P. AND LEE, S.-M., Enhanced biomass production through optimization of carbon source and utilization of wastewater as a nutrient source. Journal of Environmental Management. Vol. 184, n. 585-595, 2016.

HALIM, R., DANQUAH, M. K. AND WEBLEY, P. A., Extraction of oil from microalgae for biodiesel production: A review. Biotechnology Advances. Vol. 30, n. 3, 709-732, 2012.

HALIM, R., GLADMAN, B., DANQUAH, M. K. AND WEBLEY, P. A., Oil extraction from microalgae for biodiesel production. Bioresource Technology. Vol. 102, n. 1, 178-185, 2011.

HO, S.-H., CHANG, J.-S., LAI, Y.-Y. AND CHEN, C.-N. N., Achieving high lipid productivity of a thermotolerant microalga Desmodesmus sp. F2 by optimizing environmental factors and nutrient conditions. Bioresource Technology. Vol. 156, n. 108-116, 2014.

HU, Q., SOMMERFELD, M., JARVIS, E., GHIRARDI, M., POSEWITZ, M., SEIBERT, M. AND DARZINS, A., Microalgal triacylglycerols as feedstocks for biofuel production: perspectives and advances. The plant journal. Vol. 54, n. 4, 621-639, 2008.

HUANG, J., XIA, J., JIANG, W., LI, Y. AND LI, J., Biodiesel production from microalgae oil catalyzed by a recombinant lipase. Bioresource Technology. Vol. 180, n. 47-53, 2015.

HUGO, A. A., BRUNO, F. AND GOLOWCZYC, M. A., Whey permeate containing galacto-oligosaccharides as a medium for biomass production and spray drying of Lactobacillus plantarum CIDCA 83114. LWTfood Science and Technology. Vol. 69, n. 185-190, 2016.

LEE, J.-Y., YOO, C., JUN, S.-Y., AHN, C.-Y. AND OH, H.-M., Comparison of several methods for effective lipid extraction from microalgae. Bioresource Technology. Vol. 101, n. 1, Supplement, S75-S77, 2010. LIU, X., CLARENS, A. F. AND COLOSI, L. M., Algae biodiesel has potential despite inconclusive results to date. Bioresource technology. Vol. 104, n. 803-806, 2012.

MAHMOUD, E. A., FARAHAT, L. A., ABDEL AZIZ, Z. K., FATTHALLAH, N. A. AND SALAH EL DIN, R. A., Evaluation of the potential for some isolated microalgae to produce biodiesel. Egyptian Journal of Petroleum. Vol. 24, n. 1, 97-101, 2015.

MAHMOUD, E. A., FARAHAT, L. A., AZIZ, Z. K. A., FATTHALLAH, N. A. AND EL DIN, R. A. S., Evaluation of the potential for some isolated microalgae to produce biodiesel. Egyptian Journal of Petroleum. Vol. 24, n. 1, 97-101, 2015.

MATA, T. M., MARTINS, A. A. AND CAETANO, N. S., Microalgae for biodiesel production and other applications: A review. Renewable and Sustainable Energy Reviews. Vol. 14, n. 1, 217-232, 2010.

MORENO-GARCIA, L., ADJALLÉ, K., BARNABÉ, S. AND RAGHAVAN, G. S. V., Microalgae biomass production for a biorefinery system: Recent advances and the way towards sustainability. Renewable and Sustainable Energy Reviews. Vol. 76, n. 493-506, 2017.

PATEL, A., GAMI, B., PATEL, P. AND PATEL, B., Microalgae: Antiquity to era of integrated technology. Renewable and Sustainable Energy Reviews. Vol. 71, n. 535-547, 2017.

POHNDORF, R. S., CAMARA, Á. S., LARROSA, A. P., PINHEIRO, C. P., STRIEDER, M. M. AND PINTO, L. A., Production of lipids from microalgae Spirulina sp.: Influence of drying, cell disruption and extraction methods. Biomass and Bioenergy. Vol. 93, n. 25-32, 2016.

PRUVOST, J., VAN VOOREN, G., COGNE, G. AND LEGRAND, J., Investigation of biomass and lipids production with Neochloris oleoabundans in photobioreactor. Bioresource Technology. Vol. 100, n. 23, 5988-5995, 2009.

SANTOS, A. M., LAMERS, P. P., JANSSEN, M. AND WIJFFELS, R. H., Biomass and lipid productivity of Neochloris oleoabundans under alkaline-saline conditions. Algal Research. Vol. 2, n. 3, 204-211, 2013.

SATHISH, A., MARLAR, T. AND SIMS, R. C., Optimization of a wet microalgal lipid extraction procedure for improved lipid recovery for biofuel and bioproduct production. Bioresource Technology. Vol. 193, n. 15-24, 2015.

SHOW, K.-Y., LEE, D.-J., TAY, J.-H., LEE, T.-M. AND CHANG, J.-S., Microalgal drying and cell disruption Recent advances. Bioresource Technology. Vol. 184, n. 258-266, 2015.

SINGH, P., GULDHE, A., KUMARI, S., RAWAT, I. AND BUX, F., Investigation of combined effect of nitrogen, phosphorus and iron on lipid productivity of microalgae Ankistrodesmus falcatus KJ671624 using response surface methodology. Biochemical Engineering Journal. Vol. 94, n. 22-29, 2015. 
SONG, C., LIU, Q., JI, N., DENG, S., ZHAO, J. AND KITAMURA, Y., Intensification of microalgae drying and oil extraction process by vapor recompression and heat integration. Bioresource Technology. Vol. 207, n. 67-75, 2016. 